Article

\title{
Intraduodenal Administration of L-Valine Has No Effect on Antropyloroduodenal Pressures, Plasma Cholecystokinin Concentrations or Energy Intake in Healthy, Lean Men
}

\author{
Rachel A. Elovaris, Penelope C. E. Fitzgerald, Vida Bitarafan, Sina S. Ullrich ${ }^{\dagger}$, Michael Horowitz \\ and Christine Feinle-Bisset * \\ Adelaide Medical School and National Health and Medical Research Council of Australia Centre of Research \\ Excellence in Translating Nutritional Science to Good Health, Level 5 Adelaide Health and Medical Sciences \\ Building, Corner North Terrace and George Street, Adelaide 5005, Australia; \\ rachel.elovaris@adelaide.edu.au (R.A.E.); penelope.fitzgerald@adelaide.edu.au (P.C.E.F.); \\ vida.bitarafan@adelaide.edu.au (V.B.); sina.ullrich@uniklinik-freiburg.de (S.S.U.); \\ michael.horowitz@adelaide.edu.au (M.H.) \\ * Correspondence: christine.feinle@adelaide.edu.au; Tel.: +61-8-8313-6053 \\ + Current address: Institute for Prevention and Cancer Epidemiology, Faculty of Medicine and Medical Center, \\ University of Freiburg, 79098 Freiburg, Germany.
}

Received: 23 November 2018; Accepted: 3 January 2019; Published: 5 January 2019

check for updates

\begin{abstract}
Whey protein is rich in the branched-chain amino acids, L-leucine, L-isoleucine and L-valine. Thus, branched-chain amino acids may, at least in part, mediate the effects of whey to reduce energy intake and/or blood glucose. Notably, $10 \mathrm{~g}$ of either L-leucine or L-isoleucine, administered intragastrically before a mixed-nutrient drink, lowered postprandial blood glucose, and intraduodenal infusion of L-leucine (at a rate of $0.45 \mathrm{kcal} / \mathrm{min}$, total: $9.9 \mathrm{~g}$ ) lowered fasting blood glucose and reduced energy intake from a subsequent meal. Whether L-valine affects energy intake, and the gastrointestinal functions involved in the regulation of energy intake, as well as blood glucose, in humans, is currently unknown. We investigated the effects of intraduodenally administered L-valine on antropyloroduodenal pressures, plasma cholecystokinin, blood glucose and energy intake. Twelve healthy lean men (age: $29 \pm 2$ years, BMI: $22.5 \pm 0.7 \mathrm{~kg} / \mathrm{m}^{2}$ ) were studied on 3 separate occasions in randomised, double-blind order. Antropyloroduodenal pressures, plasma cholecystokinin, blood glucose, appetite perceptions and gastrointestinal symptoms were measured during 90-min intraduodenal infusions of L-valine at $0.15 \mathrm{kcal} / \mathrm{min}$ (total: $3.3 \mathrm{~g}$ ) or $0.45 \mathrm{kcal} / \mathrm{min}$ (total: $9.9 \mathrm{~g}$ ), or $0.9 \%$ saline (control). Energy intake from a buffet-meal immediately after the infusions was quantified. L-valine did not affect antral, pyloric (mean number; control: $14 \pm$ 5; L-Val-0.15: $21 \pm$ 9; L-Val-0.45: $11 \pm 4$ ), or duodenal pressures, plasma cholecystokinin (mean concentration, pmol/L; control: $3.1 \pm$ 0.3; L-Val-0.15: $3.2 \pm 0.3$; L-Val-0.45: $3.0 \pm 0.3$ ), blood glucose, appetite perceptions, symptoms or energy intake (kcal; control: $1040 \pm 73$; L-Val-0.15: $1040 \pm 81$; L-Val-0.45: $1056 \pm 100)$, at either load $(p>0.05$ for all). In conclusion, intraduodenal infusion of L-valine, at loads that are moderately $(3.3 \mathrm{~g})$ or substantially $(9.9 \mathrm{~g})$ above World Health Organization valine requirement recommendations, does not appear to have energy intake- or blood glucose-lowering effects.
\end{abstract}

Keywords: branched-chain amino acids; gut motility; gut hormones; appetite regulation; glycaemia; human 


\section{Introduction}

High-protein diets, when compared with diets high in carbohydrate or fat, appear to have more potent effects to decrease appetite and body weight and improve glycaemic control in obese people with and without type 2 diabetes [1-4]. Whey protein appears to be particularly effective and has been shown to decrease energy intake as well as the blood glucose response to a meal [5,6], associated with changes in gastrointestinal (GI) motor and hormone functions [7-10]. For example, administration of whey directly into the duodenum (designed to avoid the potentially confounding effects of orosensory influences and differences in gastric emptying), at rates of $0.5-3 \mathrm{kcal} / \mathrm{min}$ over $60 \mathrm{~min}$ (equivalent to 8-48 g protein), stimulated pyloric pressures, a key determinant of the slowing of gastric emptying, and the release of the gut hormones, cholecystokinin (CCK) and glucagon-like peptide-1 (GLP-1), in a dose-dependent fashion, and, at the highest rate, also suppressed energy intake [9]. In people with type 2 diabetes, managed by diet, ingestion of $55 \mathrm{~g}$ whey protein, $30 \mathrm{~min}$ before a carbohydrate meal, was shown to stimulate insulin, GLP-1 and glucose-dependent insulinotropic peptide (GIP) release and slow gastric emptying, associated with a marked reduction in postprandial glucose [11]. These effects were more marked than when the same amount of whey was co-ingested with the carbohydrate meal [11].

There is increasing evidence that, in analogy to triglycerides and fatty acids [12,13], amino acids may mediate the effects of protein, including whey, on appetite and glycaemia. Whey protein is rich in the branched-chain amino acids (BCAAs), L-leucine, L-isoleucine and L-valine. In response to intraduodenal administration of whey protein, we have observed direct correlations between plasma concentrations of these amino acids with plasma concentrations of GLP-1 and insulin, and an inverse correlation with energy intake [14], supporting the concept that these amino acids, at least in part, mediate the effects of whey to reduce energy intake and/or blood glucose. Indeed, both L-leucine and L-isoleucine have been shown in studies by ourselves and others to modulate gut motor and hormone functions, energy intake and/or blood glucose [15-19]; however, there is very little information about the effects of L-valine.

There is evidence that L-leucine decreases energy intake in both animals and humans $[15,16]$. In rats, acute injection of L-leucine, directly into the brain, inhibited food intake apparently by stimulating L-leucine-sensitive neurons in the nucleus of the solitary tract, suggesting central effects of L-leucine in the regulation of energy intake [16]. In humans, we have reported that intraduodenal infusion of L-leucine, at a rate of $0.45 \mathrm{kcal} / \mathrm{min}$ for $90 \mathrm{~min}$, stimulated plasma CCK and reduced energy intake from a subsequent meal by a substantial $156 \pm 57 \mathrm{kcal}$ [15]. Both L-leucine and L-isoleucine also decrease fasting and postprandial blood glucose. In the study referred to above [15], intraduodenal L-leucine stimulated insulin and reduced blood glucose, in the absence of carbohydrate. Moreover, $10 \mathrm{~g}$ L-leucine or L-isoleucine, ingested orally with $25 \mathrm{~g}$ of glucose $[17,18]$, or administered intragastrically 15 min before a carbohydrate-containing mixed-nutrient drink [19], attenuated the postprandial rise in blood glucose significantly.

The outcomes of studies conducted by ourselves $[19,20]$ and others $[21,22]$ indicate that the effects (and mechanisms) of amino acids to decrease appetite and glycaemia vary substantially. In fasted healthy humans, intravenous infusion of $30 \mathrm{~g}$ L-valine slightly decreased blood glucose and stimulated insulin [21]. Whether L-valine, when given at doses that are modestly ( $3.3 \mathrm{~g})$ or substantially $(9.9 \mathrm{~g})$ above World Health Organization requirement recommendations for L-valine ( $26 \mathrm{mg} / \mathrm{kg}$ body weight, equivalent to $\sim 2 \mathrm{~g}$ for a $70 \mathrm{~kg}$ person [23]), but comparable to doses that have previously been shown to be effective for L-leucine and L-isoleucine [17-19], affects energy intake, or the gut functions associated with the regulation of energy intake or blood glucose, is currently unknown.

The aim of the present study was to evaluate the hypothesis that intraduodenal infusion of L-valine would modulate plasma hormone concentrations and upper GI motility, in a dose-dependent manner, associated with reduced energy intake and fasting glucose in healthy males. 


\section{Materials and Methods}

\subsection{Participants}

Twelve healthy males, aged $29 \pm 2$ years (range: $22-43$ years) and of normal body weight (body mass index $22.5 \pm 0.7 \mathrm{~kg} / \mathrm{m}^{2}$, range: $20-25 \mathrm{~kg} / \mathrm{m}^{2}$ ) were recruited from an existing pool of volunteers and by flyers placed around the Royal Adelaide Hospital, University of Adelaide, University of South Australia and Flinders University campuses, and through advertisements in local newspapers and on online sites (University of Adelaide and Gumtree). Subjects who smoked, consumed $>20 \mathrm{~g}$ of alcohol/day, had low ferritin $(<30 \mathrm{ug} / \mathrm{L})$ or iron $(<8 \mathrm{umol} / \mathrm{L})$ concentrations, were lactose-intolerant, vegetarians, or high-performance athletes, had significant GI symptoms, disease or surgery, or used medications known to affect GI functions and/or appetite, were excluded. All subjects were unrestrained eaters (score $\leq 12$ on the eating restraint component of the Three-Factor Eating Questionnaire [24]) and had been weight-stable ( $<5 \%$ fluctuation) in the 3 months preceding the study. The study protocol was approved by the Human Research Ethics Committee of the Central Adelaide Local Health Network, and the study performed in accordance with the Declaration of Helsinki and the NHMRC Statement on Ethical Conduct in Human Research. Each subject provided written, informed consent prior to their enrolment. The study was registered as a clinical trial with the Australian New Zealand Clinical Trials Registry (www.anctr.org.au, ACTRN12617000715370).

\subsection{Study Design}

The study evaluated the dose-related effects of 90-min intraduodenal infusions of L-valine at loads of (i) $0.15 \mathrm{kcal} / \mathrm{min}$ (3.3 g over $90 \mathrm{~min}$, "L-Val-0.15”) or (ii) $0.45 \mathrm{kcal} / \mathrm{min}$ (9.9 g over $90 \mathrm{~min}$, "L-Val-0.45"), or (iii) saline ("control"), on antropyloroduodenal pressures, plasma CCK and blood glucose concentrations, appetite perceptions and energy intake in healthy male subjects.

\subsection{Intraduodenal Infusions}

L-valine solutions were prepared by dissolving $4.6 \mathrm{~g}$ or $13.8 \mathrm{~g}$ crystalline L-valine (PureBulk, Roseburg, Oregon, USA), $\mathrm{NaCl}$ (2.2 g and $0.8 \mathrm{~g}$, respectively) and $146 \mathrm{mg} \mathrm{CaCl} 2 \times 2 \mathrm{H}_{2} \mathrm{O}$, in distilled water to a final volume of $500 \mathrm{~mL}$. The control solution contained $4.8 \mathrm{~g} \mathrm{NaCl}$ and $146 \mathrm{mg} \mathrm{CaCl}_{2} \times$ $2 \mathrm{H}_{2} \mathrm{O}$ dissolved in distilled water to a volume of $500 \mathrm{~mL}$. All solutions were isotonic (300 mosmol) and had a $\mathrm{pH}$ of 7 . Intraduodenal infusions were delivered at a rate of $4 \mathrm{~mL} / \mathrm{min}$, thus, delivering loads of L-valine at $0.15 \mathrm{kcal} / \mathrm{min}$ (total: $3.3 \mathrm{~g}$ ) or $0.45 \mathrm{kcal} / \mathrm{min}$ (total: $9.9 \mathrm{~g}$ ), in a total volume over $90 \mathrm{~min}$ of $360 \mathrm{~mL}$. The loads were based on our previous study, which found significant effects of intraduodenal L-leucine on upper GI functions, blood glucose and energy intake [15]. Solutions were prepared on the morning of each study day, and were administered in a randomised, double-blind fashion. Both the preparation of the solutions and the randomisation (using an online tool [25]) were performed by a research officer, who was not involved in the performance of the studies or data analysis.

\subsection{Study Protocol}

Each subject was studied on three occasions, separated by 3-7 days. Subjects were instructed to abstain from vigorous exercise and alcohol intake for $24 \mathrm{~h}$ before each study visit. They were provided with a standardised evening meal (Beef Lasagne; McCain Food; energy content: 602 kcal) to be consumed by 7:00 p.m. on the night before each study, after which time they fasted overnight from solids and liquids. Subjects then attended the Clinical Research Facility at the University of Adelaide at 8:00 a.m. the following morning. They were intubated with a small-diameter (external diameter: $3.5 \mathrm{~mm}$ ), 17-channel manometric catheter (length: $100 \mathrm{~cm}$; Dentsleeve International, Mui Scientific, Mississauga, ON, Canada), which was inserted into the stomach through an anaesthetised nostril and allowed to pass through the pylorus into the duodenum by peristalsis $[8,26]$. The manometric catheter contained 16 side-holes spaced at $1.5 \mathrm{~cm}$ intervals and was positioned with six side-holes in the antrum (channels 1-6), a 4.5-cm sleeve sensor (channel 7), with two side-holes (channels 8,9 ) on 
the back of the sleeve, across the pylorus, and seven side-holes in the duodenum (channels 10-16). The correct positioning of the catheter, with the sleeve sensor straddling the pylorus, was maintained by continuous measurement of the transmucosal potential difference between the most distal antral, and the most proximal duodenal, channels [8,27]. An additional channel (with the side-hole positioned $\sim 14.5 \mathrm{~cm}$ distal to the pylorus when the catheter was in position) was used for intraduodenal infusion of L-valine or control solutions.

Once the catheter was positioned correctly, fasting motility was observed until the occurrence of a phase III of the migrating motor complex. Immediately after phase III passed the antropyloroduodenal region, and during a subsequent period of motor quiescence (phase I), an intravenous cannula was placed in a forearm vein for blood sampling. At $t=-10 \mathrm{~min}$ (approximately 10:30 a.m.) and $t=0 \mathrm{~min}$, fasting blood samples were taken, and the subject completed visual analogue scale (VAS) questionnaires to assess appetite perceptions and GI symptoms. The intraduodenal infusion of L-valine or control was then commenced and continued for $90 \mathrm{~min}(t=0-90 \mathrm{~min})$. Antropyloroduodenal motility was recorded continuously during the pre-infusion period and throughout the infusion, and blood samples for measurements of plasma CCK and blood glucose concentrations were collected, and VAS questionnaires completed, at 15 -min intervals. At $t=90 \mathrm{~min}$, the infusion was terminated and the catheter removed. The subject was then presented with a standardised, cold, buffet-style test meal [28]. Subjects were instructed to consume as much food as they wished until they felt comfortably full over up to $30 \mathrm{~min}(t=90-120 \mathrm{~min})$. The meal consisted of 4 slices $(\sim 120 \mathrm{~g})$ each of whole-meal and white breads, $100 \mathrm{~g}$ sliced ham, $100 \mathrm{~g}$ sliced chicken, $85 \mathrm{~g}$ sliced cheddar cheese, $100 \mathrm{~g}$ sliced tomato, $100 \mathrm{~g}$ sliced cucumber, $100 \mathrm{~g}$ iceberg lettuce, $20 \mathrm{~g}$ margarine, $22 \mathrm{~g}$ mayonnaise, $120 \mathrm{~g}$ fruit salad, $175 \mathrm{~g}$ strawberry yoghurt, $100 \mathrm{~g}$ chocolate custard, 1 apple ( $170 \mathrm{~g}), 1$ banana $(\sim 190 \mathrm{~g}), 600 \mathrm{~mL}$ water, $350 \mathrm{~mL}$ orange juice and $375 \mathrm{~mL}$ iced coffee total energy content: $\sim 2300 \mathrm{kcal}$; total weight: $\sim 2924 \mathrm{~g}$; macronutrient distribution: ( $\sim 27 \%$ fat, $\sim 52 \%$ carbohydrate and $\sim 21 \%$ protein). Immediately after the meal (i.e., at $t=120 \mathrm{~min}$ ), the intravenous catheter was removed, and the subject was then allowed to leave the laboratory.

\subsection{Measurements}

\subsubsection{Energy Intake}

Each food item in the buffet meal was weighed before and after consumption to quantify the amount of food eaten $(\mathrm{g})$. Energy intake (kcal) was then calculated using commercially available software (Foodworks 8.0, Xyris Software, Highgate Hill, Brisbane, QLD, Australia).

\subsubsection{Appetite Perceptions and GI Symptoms}

Perceptions of appetite (hunger, fullness, desire to eat and prospective food consumption) were assessed using validated 100-mm VAS questionnaires [29]. GI symptoms (nausea and bloating) were also assessed. VAS scales consisted of $100-\mathrm{mm}$ horizontal lines, where $0 \mathrm{~mm}$ represented "not felt at all", and $100 \mathrm{~mm}$ "felt the strongest possible". Subjects were asked to place a vertical mark on each horizontal line to rate the strength of each sensation felt at that point in time.

\subsubsection{Antropyloroduodenal Pressures}

Antropyloroduodenal pressures were digitised and recorded via a computer-based system running commercially available software (MMS Database software, version 8.17; Solar GI, Enschede, The Netherlands). Antropyloroduodenal pressures were analysed for: (i) numbers and amplitudes of antral and duodenal pressure waves (PWs); (ii) numbers and amplitudes of isolated pyloric pressure waves (IPPWs); and (iii) basal pyloric pressure. Pressure waves were defined by an amplitude $\geq 10 \mathrm{mmHg}$, and a minimum interval of $15 \mathrm{~s}$ between peaks for antral and pyloric waves and $3 \mathrm{~s}$ for duodenal waves. Basal pyloric pressure was calculated by subtracting the mean basal pressure (with the exclusion of phasic pressures) recorded at the most distal antral side hole from the mean 
basal pressure recorded at the sleeve [27]. This analysis was performed using custom-written software (by Prof. A. Smout, University Medical Centre, Amsterdam, The Netherlands).

\subsubsection{Plasma CCK and Blood Glucose Concentrations}

Blood samples were collected into ice-chilled ethylenediaminetetraacetic acid-coated tubes and centrifuged (3200 rpm at $4{ }^{\circ} \mathrm{C}$ for $15 \mathrm{~min}$ ) within $15 \mathrm{~min}$ of collection to obtain plasma. Plasma samples were stored at $-80^{\circ} \mathrm{C}$ until analysed. Plasma cholecystokinin-8 (CCK-8) concentrations (pmol/L) were analysed by radioimmunoassay after ethanol extraction using an adaption of the method by Santangelo et al. [30]. The antibody used recognises sulfated CCK-8 and does not bind to structurally unrelated peptides. Cross-reactivity with unsulfated CCK-8 was $\sim 15 \%$ and with human gastrin I $0.2 \%$. The detection limit was $1 \mathrm{pmol} / \mathrm{L}$, and intra-assay and inter-assay coefficients of variation were $9.2 \%$ and $13.7 \%$, respectively.

Blood glucose concentrations $(\mathrm{mmol} / \mathrm{L})$ were determined immediately after collection by the glucose oxidase method using a portable glucometer (FreeStyle OptimumH; Abbott Laboratories, Chicago, IL, USA).

\subsection{Data and Statistical Analyses}

The number of subjects was based on power calculations derived from previous work [15]. We calculated that $n=12$ subjects would be required to detect a $15 \%$ decrease in energy intake at $\alpha=0.05$, with a power of $80 \%$.

For all data baseline values were calculated as means of values acquired between $t=-10$ and $t=0 \mathrm{~min}$. During the 90-min infusion period, VAS scores, plasma CCK and blood glucose data were expressed as means at each time point, while the number of antral, isolated pyloric and duodenal PWs were expressed as total numbers, and basal pyloric pressures and the amplitude of antral, isolated pyloric and duodenal PWs, were expressed as mean values over the $90-\mathrm{min}$ period. The numbers and amplitudes of antral and duodenal PWs were used to calculate antral and duodenal motility indices (MIs), as previously described [31].

Statistical analysis was performed with the use of SPSS software (version 24; IBM, Armonk, NY, USA). VAS scores, plasma CCK and blood glucose data were analysed using repeated-measures two-factor analysis of variance (ANOVA), with time (0-90 min), and treatment (L-valine-0.15, L-valine-0.45, control) as factors. MIs for antral and duodenal PWs, basal pyloric pressure, number and amplitude of IPPWs and energy intake were analysed using one-factor ANOVA. Sphericity of the time effect for all models was evaluated by Mauchly's test, and, if violated, the adjusted Greenhouse-Geisser $p$ value was reported. Post-hoc comparisons, adjusted for multiple comparisons by Bonferroni correction, were performed where ANOVAs revealed significant effects. All data are reported as means $\pm \mathrm{SEMs}$. All tests were two-tailed and statistical significance was accepted at $p<0.05$.

\section{Results}

All subjects completed the 3 study visits and tolerated the study treatments well.

\subsection{Energy Intake}

There was no effect of treatment on energy intake (Figure 1), or the amount eaten (gram; control: $1198 \pm 94$; L-Val-0.15: $1156 \pm 83$; L-Val-0.45: $1156 \pm 97)$, from the buffet-meal ( $p>0.05$ for both).

\subsection{Appetite Perceptions and GI Symptoms}

There were no differences in baseline ratings of hunger, fullness, desire to eat, prospective consumption, bloating or nausea between study days. There were also no effects of treatment or time on ratings of these sensations and symptoms ( $p>0.05$ for all; Figure 2A-F). 


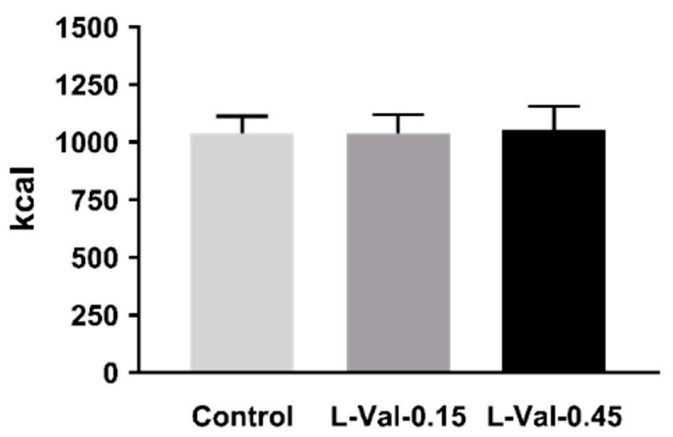

Figure 1. Energy intake from a buffet meal after 90-min intraduodenal infusions of control, or L-valine at $0.15 \mathrm{kcal} / \mathrm{min}$ (“L-Val-0.15") or $0.45 \mathrm{kcal} / \mathrm{min}$ ("L-Val-0.45”). One-way ANOVA was used to analyse the data. Statistical significance was accepted at $p<0.05$. Data are means \pm SEMs, $n=12$.
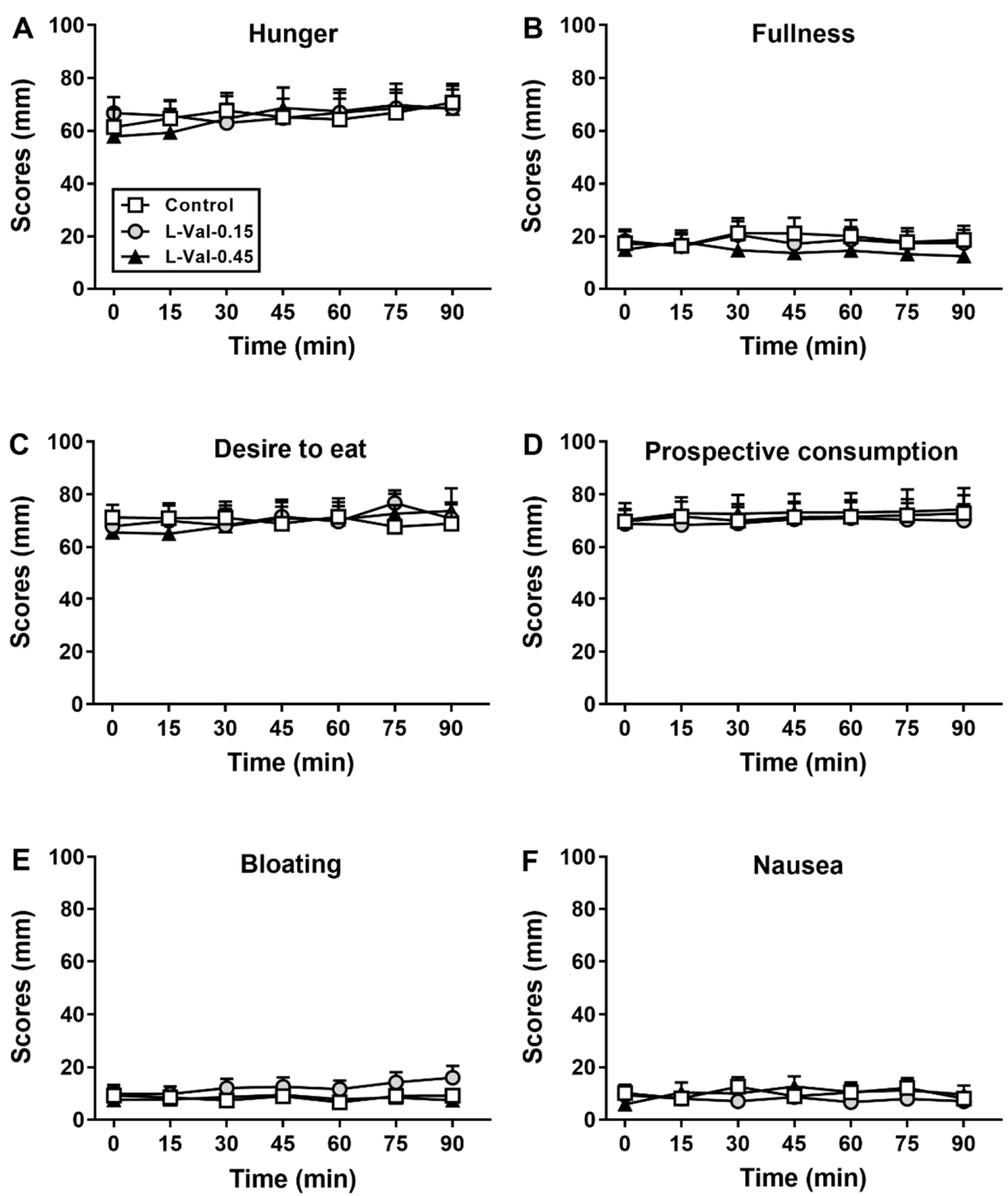

Figure 2. Scores for hunger (A), fullness (B), desire to eat (C), prospective consumption (D), bloating (E) and nausea (F) during 90-min intraduodenal infusions of L-valine at $0.15 \mathrm{kcal} / \mathrm{min}$ ("L-Val-0.15") or $0.45 \mathrm{kcal} / \mathrm{min}$ ("L-Val-0.45"), or control. Repeated-measures two-factor ANOVA, with treatment and time as factors, was used to analyse the data. Post-hoc comparisons, adjusted for multiple comparisons by Bonferroni correction, were used to determine significant differences between treatments if ANOVAs were significant. Statistical significance was accepted at $p<0.05$. Data are means \pm SEMs, $n=12$. 


\subsection{Antropyloroduodenal Pressures}

Baseline values for antral, pyloric and duodenal pressures did not differ between study days and were 0 ( $p>0.05$ for all).

There was no effect of treatment on the total number, mean amplitude or MI of antral PWs; mean basal pyloric pressures; total number or mean amplitude of IPPWs, or the total number, mean amplitude or MI of duodenal PWs ( $p>0.05$ for all; Table 1).

Table 1. Number, amplitude and motility indices of antral and duodenal pressure waves, basal pyloric pressure, and number and amplitude of isolated pyloric pressures waves during 90-min intraduodenal infusions of L-valine at $0.15 \mathrm{kcal} / \mathrm{min}$ ("L-Val-0.15"), L-valine at $0.45 \mathrm{kcal} / \mathrm{min}$ ("L-Val- 0.45 "), or control.

\begin{tabular}{|c|c|c|c|c|}
\hline & Control & L-Val-0.15 & L-Val-0.45 & $p$ Value \\
\hline \multicolumn{5}{|l|}{ Antral pressure waves } \\
\hline Number & $51 \pm 18$ & $46 \pm 11$ & $35 \pm 11$ & $>0.05$ \\
\hline Amplitude, $m m H g$ & $37 \pm 8$ & $46 \pm 8$ & $34 \pm 7$ & $>0.05$ \\
\hline Motility index, $\mathrm{mmHg} \times$ min & $9 \pm 1$ & $10 \pm 1$ & $9 \pm 1$ & $>0.05$ \\
\hline Basal pyloric pressure, $\mathrm{mmHg}$ & $-0.3 \pm 0.9$ & $0.2 \pm 1.0$ & $0.4 \pm 0.4$ & $>0.05$ \\
\hline \multicolumn{5}{|l|}{ Isolated pyloric pressure waves } \\
\hline Number & $14 \pm 5$ & $21 \pm 9$ & $11 \pm 4$ & $>0.05$ \\
\hline Amplitude, $m m H g$ & $9 \pm 3$ & $16 \pm 4$ & $14 \pm 4$ & $>0.05$ \\
\hline \multicolumn{5}{|l|}{ Duodenal pressure waves } \\
\hline Number & $445 \pm 66$ & $495 \pm 77$ & $361 \pm 65$ & $>0.05$ \\
\hline Amplitude, $m m H g$ & $29 \pm 2$ & $29 \pm 3$ & $27 \pm 2$ & $>0.05$ \\
\hline Motility index, $\mathrm{mmHg} \times \mathrm{min}$ & $15 \pm 0.4$ & $15 \pm 0.4$ & $14 \pm 0.5$ & $>0.05$ \\
\hline
\end{tabular}

One-factor ANOVA was used to test for differences in number, amplitude and motility indices of antral and duodenal pressure waves, basal pyloric pressure, and number and amplitude of isolated pyloric pressures waves. Post-hoc comparisons, adjusted for multiple comparisons by Bonferroni's correction, were used to determine significant differences between treatments if ANOVAs were significant. Data are means \pm SEMs, $n=12$.

\subsection{Plasma CCK and Blood Glucose Concentrations}

There were no differences in baseline values between study days for plasma CCK or blood glucose concentrations $(p>0.05$ for all).

There was no effect of treatment $(p>0.05)$, but an effect of time $(p<0.05)$, on plasma CCK concentrations (Figure 3A). All 3 infusions slightly increased plasma CCK at $t=15 \min (p<0.05)$, after which time no further changes occurred.

There was no effect of treatment, or time, on blood glucose concentrations ( $p>0.05$; Figure 3B).
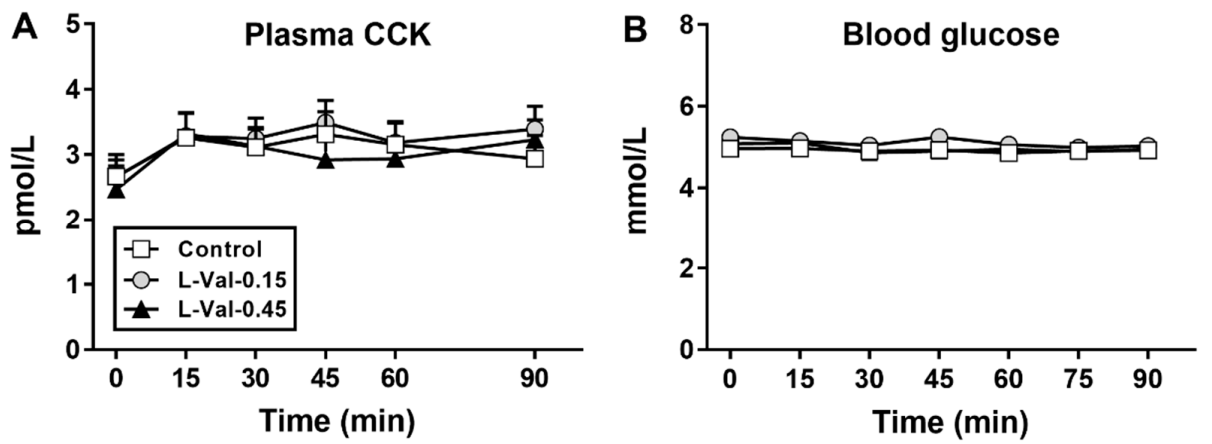

Figure 3. Plasma CCK (A) and blood glucose (B) concentrations during 90-min intraduodenal infusions of L-valine at $0.15 \mathrm{kcal} / \mathrm{min}$ ("L-Val-0.15") or $0.45 \mathrm{kcal} / \mathrm{min}$ ("L-Val-0.45"), or control. Repeated-measures two-factor ANOVA, with treatment and time as factors, was used to analyse the data. Post-hoc comparisons, adjusted for multiple comparisons by Bonferroni correction, were used to determine significant differences between treatments if ANOVAs were significant. Statistical significance was accepted at $p<0.05$. Data are means \pm SEMs, $n=11$ for CCK (due to technical difficulties with blood sampling), $n=12$ for glucose. 


\section{Discussion}

We have investigated the effects of the BCAA, L-valine, which is abundant in whey protein, to elucidate whether L-valine, like L-leucine and L-isoleucine, has potent effects to reduce energy intake and/or blood glucose and to modulate key underlying GI functions. Our study indicates that L-valine, when administered intraduodenally at loads of $0.15 \mathrm{kcal} / \mathrm{min}$ or $0.45 \mathrm{kcal} / \mathrm{min}$ for $90 \mathrm{~min}$, has no effect on antropyloroduodenal motility, plasma CCK, energy intake or blood glucose, suggesting that L-valine, unlike L-leucine at these loads, does not have GI, energy intake-suppressant or glucoregulatory effects.

There has been substantial interest in BCAAs, particularly L-leucine and L-isoleucine, in relation to their potential role in mediating the effects of protein, particularly whey, on energy intake, blood glucose and other metabolic outcomes [4,22]. We have reported recently that intraduodenal infusion of L-leucine at the load of $0.45 \mathrm{kcal} / \mathrm{min}$, but not $0.15 \mathrm{kcal} / \mathrm{min}$ (loads identical to those used in the current study), significantly reduced subsequent energy intake, associated with stimulation of plasma CCK concentrations, in healthy males [15]. We have also reported that, in response to intraduodenal whey protein, subsequent energy intake is correlated inversely with circulating concentrations of L-leucine, L-isoleucine and L-valine [14]. Based on these findings, we hypothesised that intraduodenal infusion of L-valine would also reduce energy intake. In contrast to our expectation, L-valine was ineffective-it did not affect subsequent energy intake, nor GI functions of relevance to the regulation of energy intake, specifically the stimulation of plasma CCK and pyloric pressures [32,33]. While it is possible that L-valine may be an amino acid that does not play a role in appetite regulation, it is worth noting the important contributory roles of orosensory and gastric influences (which we bypassed in the current study) with gut hormone release and the modulation of energy intake [34,35]. In support, while oral administration of L-phenylalanine has been shown to reduce subsequent energy intake in healthy humans [36], we reported recently that intraduodenal L-phenylalanine was ineffective [37]. Thus, the effects of orally administered L-valine, and, if effective, potential underlying mechanisms, warrant further investigation.

Studies in healthy individuals have established the capacity of both L-leucine and L-isoleucine to reduce elevated blood glucose levels. For example, intragastric administration of $10 \mathrm{~g}$ L-leucine or $10 \mathrm{~g}$ L-isoleucine, $15 \mathrm{~min}$ before consumption of a carbohydrate-containing mixed-nutrient drink, reduced the blood glucose response to the drink by $\sim 1.1 \mathrm{mmol} / \mathrm{L}$ [19]. Furthermore, intraduodenal infusion of leucine at $0.45 \mathrm{kcal} / \mathrm{min}(9.9 \mathrm{~g}$ over $90 \mathrm{~min})$, slightly stimulated insulin and reduced fasting blood glucose modestly [15]. In contrast to L-leucine and L-isoleucine, the few studies on the effects of valine on blood glucose have yielded inconsistent findings [22]. In fasted rats, L-valine $(0.3 \mathrm{~g} / \mathrm{kg}$ body weight, equivalent to $\sim 22.5 \mathrm{~g}$ in a $75 \mathrm{~kg}$ human), given orally $30 \mathrm{~min}$ before an oral glucose tolerance test, increased plasma glucose levels, $60 \mathrm{~min}$ later by $\sim 20 \mathrm{mg} / \mathrm{dl}$ [38], and, at a dose of $1 \mathrm{~g} / \mathrm{kg}$ body weight, ameliorated the fall in blood glucose induced by exercise [39], while, in contrast, intrahypothalamic infusion of L-valine $(12 \mathrm{nmol})$, given with a continuous intravenous glucose infusion, was reported to lower blood glucose [40], compared with control rats. In fasted healthy humans, intravenous administration of $30 \mathrm{~g}$ L-valine resulted in a small stimulation of insulin secretion and decrease in blood glucose concentrations [21]. The L-valine loads used in these studies were extremely high. Moreover, the discrepant effects may be due to species differences (rats vs. humans), as well as the different routes of administration (oral vs. intravenous vs. intrahypothalamic). Our data, using doses spanning physiological and supraphysiological ranges, found no effects on blood glucose concentrations. It should be appreciated that our study design did not include a carbohydrate-containing meal or oral administration of L-valine, and, thus, did not evaluate effects on postprandial blood glucose. This also warrants evaluation.

Some limitations of our study should be recognised. We did not measure all of the key gut and pancreatic hormones involved in energy intake or blood glucose regulation, including ghrelin, peptide tyrosine tyrosine, GLP-1, GIP, insulin and glucagon, because of the lack of effect of L-valine on energy intake, blood glucose and plasma CCK concentrations. Intraduodenal infusion of L-valine 
was used to exclude influences of orosensory factors and to standardise nutrient delivery to the small intestine, bypassing any inter-individual variations in gastric emptying. Thus, we cannot exclude the possibility that L-valine affects energy intake and/or blood glucose when ingested orally or administered intragastrically, thus, activating multiple afferent pathways concurrently [41,42]. We administered L-valine in isolation, thus, the apparent discrepancy in our findings, i.e., a lack of effect of intraduodenally administered L-valine on energy intake, versus the inverse correlation between plasma L-valine concentrations and energy intake after intraduodenal whey protein infusion in our previous study [14], may indicate that L-valine requires the presence of other amino acids to exert an effect on energy intake and/or blood glucose; this hypothesis may also warrant investigation. Finally, we only studied healthy males, because they have been reported to be most sensitive to dietary manipulations [43], hence, we cannot generalise our findings to outcomes in women, overweight/obese or age, however, we believe a different outcome would be unlikely.

In conclusion, intraduodenal infusions of L-valine, at loads that are moderately (3.3 g) or substantially (9.9 g) above World Health Organization requirement recommendations, do not affect antropyloroduodenal motility, plasma CCK or fasting blood glucose concentrations, or energy intake. These observations indicate that, unlike L-leucine or L-isoleucine, L-valine, does not play a critical role in the regulation of energy intake and/or blood glucose control, providing evidence that different amino acids, even though of similar chemical structure, can have distinct physiological effects.

Author Contributions: Conceptualization, S.S.U., M.H. and C.F.-B.; Data curation, R.A.E. and V.B.; Formal analysis, R.A.E.; Funding acquisition, C.F.-B.; Investigation, R.A.E., P.C.E.F. and V.B.; Project administration, P.C.E.F. and C.F.-B.; Resources, C.F.-B.; Supervision, P.C.E.F., M.H. and C.F.-B.; Validation, R.A.E., V.B. and C.F.-B.; Visualization, R.A.E.; Writing-original draft, R.A.E. and C.F.-B.; Writing-review \& editing, P.C.E.F., V.B., S.S.U., M.H. and C.F.-B.

Funding: R.A.E. was supported by a Research Training Scholarship from the University of Adelaide (2017-20), V.B. by an International PhD Scholarship from the University of Adelaide (2017-20), S.S.U. by an Australian Government Research Training Program Scholarship (2014-17) and C.F.B. by an NHMRC Senior Research Fellowship (grant 1103020, 2016-21). The research was supported by an NHMRC Project Grant (grant no 1078471, 2015-19, to C.F.B.).

Acknowledgments: We thank Kylie Lange, NHMRC Centre of Research Excellence in Translating Nutritional Science to Good Health, The University of Adelaide, a biostatistician, for statistical support and Scott Standfield for performing the biochemical assay for cholecystokinin.

Conflicts of Interest: The authors declare no conflict of interest. The sponsors had no role in the design of the study, the collection, analyses, or interpretation of data, writing of the manuscript, and in the decision to publish the results.

\section{References}

1. Farnsworth, E.; Luscombe, N.D.; Noakes, M.; Wittert, G.; Argyiou, E.; Clifton, P.M. Effect of a high-protein, energy-restricted diet on body composition, glycemic control, and lipid concentrations in overweight and obese hyperinsulinemic men and women. Am. J. Clin. Nutr. 2003, 78, 31-39. [CrossRef] [PubMed]

2. Aller, E.E.; Larsen, T.M.; Claus, H.; Lindroos, A.K.; Kafatos, A.; Pfeiffer, A.; Martinez, J.A.; Handjieva-Darlenska, T.; Kunesova, M.; Stender, S.; et al. Weight loss maintenance in overweight subjects on ad libitum diets with high or low protein content and glycemic index: The DIOGENES trial 12-month results. Int. J. Obes. (Lond.) 2014, 38, 1511-1517. [CrossRef] [PubMed]

3. Veldhorst, M.; Smeets, A.; Soenen, S.; Hochstenbach-Waelen, A.; Hursel, R.; Diepvens, K.; Lejeune, M.; Luscombe-Marsh, N.; Westerterp-Plantenga, M. Protein-induced satiety: Effects and mechanisms of different proteins. Physiol. Behav. 2008, 94, 300-307. [CrossRef] [PubMed]

4. Layman, D.K.; Baum, J.I. Dietary protein impact on glycemic control during weight loss. J. Nutr. 2004, 134, 968S-973S. [CrossRef] [PubMed]

5. Pal, S.; Ellis, V. The acute effects of four protein meals on insulin, glucose, appetite and energy intake in lean men. Br. J. Nutr. 2010, 104, 1241-1248. [CrossRef] [PubMed]

6. Anderson, G.H.; Tecimer, S.N.; Shah, D.; Zafar, T.A. Protein source, quantity, and time of consumption determine the effect of proteins on short-term food intake in young men. J. Nutr. 2004, 134, 3011-3015. [CrossRef] 
7. Lejeune, M.P.; Westerterp, K.R.; Adam, T.C.; Luscombe-Marsh, N.D.; Westerterp-Plantenga, M.S. Ghrelin and glucagon-like peptide 1 concentrations, 24-h satiety, and energy and substrate metabolism during a high-protein diet and measured in a respiration chamber. Am. J. Clin. Nutr. 2006, 83, 89-94. [CrossRef]

8. Ryan, A.T.; Luscombe-Marsh, N.D.; Saies, A.A.; Little, T.J.; Standfield, S.; Horowitz, M.; Feinle-Bisset, C. Effects of intraduodenal lipid and protein on gut motility and hormone release, glycemia, appetite, and energy intake in lean men. Am. J. Clin. Nutr. 2013, 98, 300-311. [CrossRef]

9. Ryan, A.T.; Feinle-Bisset, C.; Kallas, A.; Wishart, J.M.; Clifton, P.M.; Horowitz, M.; Luscombe-Marsh, N.D. Intraduodenal protein modulates antropyloroduodenal motility, hormone release, glycemia, appetite, and energy intake in lean men. Am. J. Clin. Nutr. 2012, 96, 474-482. [CrossRef]

10. Hutchison, A.T.; Piscitelli, D.; Horowitz, M.; Jones, K.L.; Clifton, P.M.; Standfield, S.; Hausken, T.; Feinle-Bisset, C.; Luscombe-Marsh, N.D. Acute load-dependent effects of oral whey protein on gastric emptying, gut hormone release, glycemia, appetite, and energy intake in healthy men. Am. J. Clin. Nutr. 2015, 102, 1574-1584. [CrossRef]

11. Ma, J.; Stevens, J.E.; Cukier, K.; Maddox, A.F.; Wishart, J.M.; Jones, K.L.; Clifton, P.M.; Horowitz, M.; Rayner, C.K. Effects of a protein preload on gastric emptying, glycemia, and gut hormones after a carbohydrate meal in diet-controlled type 2 diabetes. Diabetes Care 2009, 32, 1600-1602. [CrossRef] [PubMed]

12. Feinle, C.; O'Donovan, D.; Doran, S.; Andrews, J.M.; Wishart, J.; Chapman, I.; Horowitz, M. Effects of fat digestion on appetite, APD motility, and gut hormones in response to duodenal fat infusion in humans. Am. J. Physiol. Gastrointest. Liver Physiol. 2003, 284, G798-G807. [CrossRef] [PubMed]

13. Pilichiewicz, A.; O’Donovan, D.; Feinle, C.; Lei, Y.; Wishart, J.M.; Bryant, L.; Meyer, J.H.; Horowitz, M.; Jones, K.L. Effect of lipase inhibition on gastric emptying of, and the glycemic and incretin responses to, an oil/aqueous drink in type 2 diabetes mellitus. J. Clin. Endocrinol. Metab. 2003, 88, 3829-3834. [CrossRef] [PubMed]

14. Luscombe-Marsh, N.D.; Hutchison, A.T.; Soenen, S.; Steinert, R.E.; Clifton, P.M.; Horowitz, M.; Feinle-Bisset, C. Plasma free amino acid responses to intraduodenal whey protein, and relationships with insulin, glucagon-like peptide-1 and energy intake in lean healthy men. Nutrients 2016, 8, 4. [CrossRef] [PubMed]

15. Steinert, R.E.; Landrock, M.F.; Ullrich, S.S.; Standfield, S.; Otto, B.; Horowitz, M.; Feinle-Bisset, C. Effects of intraduodenal infusion of the branched-chain amino acid leucine on ad libitum eating, gut motor and hormone functions, and glycemia in healthy men. Am. J. Clin. Nutr. 2015, 102, 820-827. [CrossRef] [PubMed]

16. Cota, D.; Proulx, K.; Smith, K.A.; Kozma, S.C.; Thomas, G.; Woods, S.C.; Seeley, R.J. Hypothalamic mTOR signaling regulates food intake. Science 2006, 312, 927-930. [CrossRef] [PubMed]

17. Kalogeropoulou, D.; Lafave, L.; Schweim, K.; Gannon, M.C.; Nuttall, F.Q. Leucine, when ingested with glucose, synergistically stimulates insulin secretion and lowers blood glucose. Metabolism 2008, 57, 1747-1752. [CrossRef]

18. Nuttall, F.Q.; Schweim, K.; Gannon, M.C. Effect of orally administered isoleucine with and without glucose on insulin, glucagon and glucose concentrations in non-diabetic subjects. Eur. J. Clin. Nutr. Metab. 2008, 3, e152-e158. [CrossRef]

19. Ullrich, S.S.; Fitzgerald, P.C.; Schober, G.; Steinert, R.E.; Horowitz, M.; Feinle-Bisset, C. Intragastric administration of leucine or isoleucine lowers the blood glucose response to a mixed-nutrient drink by different mechanisms in healthy, lean volunteers. Am. J. Clin. Nutr. 2016, 104, 1274-1284. [CrossRef]

20. Ullrich, S.S.; Fitzgerald, P.C.; Nkamba, I.; Steinert, R.E.; Horowitz, M.; Feinle-Bisset, C. Intragastric Lysine Lowers the Circulating Glucose and Insulin Responses to a Mixed-Nutrient Drink without Slowing Gastric Emptying in Healthy Adults. J. Nutr. 2017, 147, 1275-1281. [CrossRef]

21. Floyd, J.C., Jr.; Fajans, S.S.; Conn, J.W.; Knopf, R.F.; Rull, J. Stimulation of insulin secretion by amino acids. J. Clin. Investig. 1966, 45, 1487-1502. [CrossRef] [PubMed]

22. Chartrand, D.; Da Silva, M.S.; Julien, P.; Rudkowska, I. Influence of amino acids in dairy products on glucose homeostasis: The clinical evidence. Can. J. Diabetes 2017, 41, 329-337. [CrossRef] [PubMed]

23. Protein and Amino Acid Requirements in Human Nutrition: Report of a Joint FAO/WHO/UNU Expert Consultation. Available online: http:/ / www.who.int/iris/handle/10665/43411 (accessed on 2 January 2019).

24. Stunkard, A.J.; Messick, S. The three-factor eating questionnaire to measure dietary restraint, disinhibition and hunger. J. Psychosom. Res. 1985, 29, 71-83. [CrossRef]

25. Randomization.com. Available online: www.randomization.com (accessed on 8 May 2017). 
26. Feltrin, K.L.; Little, T.J.; Meyer, J.H.; Horowitz, M.; Smout, A.J.; Wishart, J.; Pilichiewicz, A.N.; Rades, T.; Chapman, I.M.; Feinle-Bisset, C. Effects of intraduodenal fatty acids on appetite, antropyloroduodenal motility, and plasma CCK and GLP-1 in humans vary with their chain length. Am. J. Physiol. Regul. Integr. Comp. Physiol. 2004, 287, R524-R533. [CrossRef] [PubMed]

27. Heddle, R.; Dent, J.; Toouli, J.; Read, N.W. Topography and measurement of pyloric pressure waves and tone in humans. Am. J. Physiol. 1988, 255, G490-G497. [CrossRef] [PubMed]

28. Nair, N.S.; Brennan, I.M.; Little, T.J.; Gentilcore, D.; Hausken, T.; Jones, K.L.; Wishart, J.M.; Horowitz, M.; Feinle-Bisset, C. Reproducibility of energy intake, gastric emptying, blood glucose, plasma insulin and cholecystokinin responses in healthy young males. Br. J. Nutr. 2009, 101, 1094-1102. [CrossRef] [PubMed]

29. Parker, B.; Sturm, K.; MacIntosh, C.; Feinle, C.; Horowitz, M.; Chapman, I. Relation between food intake and visual analogue scale ratings of appetite and other sensations in healthy older and young subjects. Eur. J. Clin. Nutr. 2004, 58, 212-218. [CrossRef]

30. Santangelo, A.; Peracchi, M.; Conte, D.; Fraquelli, M.; Porrini, M. Physical state of meal affects gastric emptying, cholecystokinin release and satiety. Br. J. Nutr. 1998, 80, 521-527. [CrossRef]

31. Camilleri, M.; Malagelada, J.R. Abnormal intestinal motility in diabetics with the gastroparesis syndrome. Eur. J. Clin. Investig. 1984, 14, 420-427. [CrossRef]

32. Seimon, R.V.; Lange, K.; Little, T.J.; Brennan, I.M.; Pilichiewicz, A.N.; Feltrin, K.L.; Smeets, A.J.; Horowitz, M.; Feinle-Bisset, C. Pooled-data analysis identifies pyloric pressures and plasma cholecystokinin concentrations as major determinants of acute energy intake in healthy, lean men. Am. J. Clin. Nutr. 2010, 92, 61-68. [CrossRef]

33. Schober, G.; Lange, K.; Steinert, R.E.; Hutchison, A.T.; Luscombe-Marsh, N.D.; Landrock, M.F.; Horowitz, M.; Seimon, R.V.; Feinle-Bisset, C. Contributions of upper gut hormones and motility to the energy intake-suppressant effects of intraduodenal nutrients in healthy, lean men-A pooled-data analysis. Physiol. Rep. 2016, 4, e12943. [CrossRef] [PubMed]

34. Kissileff, H.R.; Carretta, J.C.; Geliebter, A.; Pi-Sunyer, F.X. Cholecystokinin and stomach distension combine to reduce food intake in humans. Am. J. Physiol. Regul. Integr. Comp. Physiol. 2003, 285, R992-R998. [CrossRef] [PubMed]

35. Koop, I.; Ruppert-Seipp, G.; Koop, H.; Schafmayer, A.; Arnold, R. Cholecystokinin release by gastric distension-An atropine-sensitive mechanism. Digestion 1990, 46, 220-227. [CrossRef] [PubMed]

36. Ballinger, A.B.; Clark, M.L. L-phenylalanine releases cholecystokinin (CCK) and is associated with reduced food intake in humans: Evidence for a physiological role of CCK in control of eating. Metabolism 1994, 43, 735-738. [CrossRef]

37. Steinert, R.E.; Ullrich, S.S.; Geary, N.; Asarian, L.; Bueter, M.; Horowitz, M.; Feinle-Bisset, C. Comparative effects of intraduodenal amino acid infusions on food intake and gut hormone release in healthy males. Physiol. Rep. 2017, 5, e13492. [CrossRef] [PubMed]

38. Doi, M.; Yamaoka, I.; Fukunaga, T.; Nakayama, M. Isoleucine, a potent plasma glucose-lowering amino acid, stimulates glucose uptake in C2C12 myotubes. Biochem. Biophys. Res. Commun. 2003, 312, 1111-1117. [CrossRef] [PubMed]

39. Tsuda, Y.; Iwasawa, K.; Yamaguchi, M. Acute supplementation of valine reduces fatigue during swimming exercise in rats. Biosci. Biotechnol. Biochem. 2018, 82, 856-861. [CrossRef]

40. Arrieta-Cruz, I.; Su, Y.; Gutierrez-Juarez, R. Suppression of endogenous glucose production by isoleucine and valine and impact of diet composition. Nutrients 2016, 8, 79. [CrossRef]

41. Depoortere, I. Taste receptors of the gut: Emerging roles in health and disease. Gut 2014, 63, 179-190. [CrossRef]

42. Latorre, R.; Sternini, C.; De Giorgio, R.; Greenwood-Van Meerveld, B. Enteroendocrine cells: A review of their role in brain-gut communication. Neurogastroenterol. Motil. 2016, 28, 620-630. [CrossRef]

43. Rolls, B.J.; Kim-Harris, S.; Fischman, M.W.; Foltin, R.W.; Moran, T.H.; Stoner, S.A. Satiety after preloads with different amounts of fat and carbohydrate: Implications for obesity. Am. J. Clin. Nutr. 1994, 60, 476-487. [CrossRef] [PubMed]

(C) 2019 by the authors. Licensee MDPI, Basel, Switzerland. This article is an open access article distributed under the terms and conditions of the Creative Commons Attribution (CC BY) license (http:/ / creativecommons.org/licenses/by/4.0/). 